\title{
FORMAÇÃO ESCOLAR E FORMAÇÃO ESPORTIVA: CAMINHOS APRESENTADOS PELA PRODUÇÃO ACADÊMICA
}

\author{
SCHOOL EDUCATION AND SPORTS TRAINING: PATHWAYS PRESENTED BY \\ ACADEMIC PRODUCTION
}

\author{
FORMACIÓN ESCOLAR Y FORMACIÓN DEPORTIVA: CAMINOS \\ PRESENTADOS POR LA PRODUCCIÓN ACADÉMICA
}

\author{
Márcio Faria de Azevedo*, Wagner dos Santos ${ }^{\star *}$, Felipe Rodrigues da Costa***, \\ Antonio Jorge Gonçalves Soares ${ }^{\star \star \star *}$
}

\section{Palavras chave:}

Esportes.

Indicadores de Educação Física e treinamento. produção cientifica

\begin{abstract}
Resumo: Objetiva mapear as produções acadêmicas que discutem a conciliação entre formação escolar e formação esportiva. Utiliza como fonte a base de dados SciELO para busca nacional e o Portal Periódicos Capes para busca internacional. Foram mapeados dezessete artigos distribuídos em treze periódicos. Os dados foram classificados/ analisados por meio de indicadores bibliométricos. Para análise e discussões, consideramos ainda uma tese de doutorado, quatro dissertações de mestrado e três trabalhos apresentados em congresso, além de um número especial de periódico, não localizado nas bases escolhidas. Mostra que a preocupação com o tema surge na Europa e nos Estados Unidos, na década de 1970 e que, no Brasil, passa a ser abordado na década de 2000. Apresenta tentativas de conciliação entre as formações realizadas na Europa, nos Estados Unidos e no Brasil e a importância de fatores externos na possibilidade de priorização de uma das formações envolvidas.
\end{abstract}

Keywords: Sports. Scientific publication indicators. Physical Education training.

Palabras clave: Deportes. Indicadores de producción científica Educación Física y entrenamiento.
Abstract: This article maps academic works about reconciling school education and sports education. Its sources included the SciElo database for national search and Capes Portal for international search. Seventeen articles were mapped in thirteen journals. Data were classified/analyzed through bibliometric indicators. Analyses and discussions also covered one doctoral thesis, four master's dissertations, and three studies presented at congresses, in addition to the special issue of a journal not found in those databases. It shows that concern with the issue emerged in Europe and the US in the 1970s, and it started to be debated in Brazil in the 2000s. It points at attempts to reconcile education acquired in Europe, the US and Brazil, and the importance of external factors for the possibility of ascribing priority to one of the educations concerned.

Resumen: Tiene por objetivo mapear las producciones académicas que discuten la conciliación entre formación escolar y formación deportiva. Utiliza como fuente la base de datos SciElo a nivel nacional y el Portal Capes a nivel internacional. Se consultaron diecisiete artículos distribuidos en trece periódicos académicos. Los datos se clasificaron/ analizaron según indicadores bibliométricos. Para el análisis y las discusiones consideramos, además, una tesis doctoral, cuatro disertaciones de maestría y tres trabajos presentados en congresos, además de un número especial de un periódico académico que no fue localizado en las bases de datos elegidas. Muestra que la preocupación sobre ese tema surge en Europa y Estados Unidos, en la década de los 70, y que en Brasil pasa a ser abordado en los años 2000. Presenta los intentos de conciliación entre las formaciones realizadas en Europa, Estados Unidos y Brasil, así como la importancia de factores externos en la posibilidad de dar prioridad a una de esas formaciones.
*Universidade Vila Velha. Vila Velha, ES, Brasil.

E-mail: mazevedo.personal@gmail.com

** Universidade Federal do Espírito Santo. Vitoria ES, Brasil.

E-mail:wagnercefd@gmail.com

*** Universidade de Brasília. Brasília, DF, Brasil.

E-mail: fcostavix@gmail.com

**** Universidade Federal do Rio de Janeiro. Rio de Janeiro, RJ, Brasil. E-mail: ajgsoares@gmail.com

Recebido em: 01-01-2016 Aprovado em: 06-14-2016

(c) (1) (3) Licence 


\section{INTRODUÇÃO}

O ciclo de megaeventos esportivos em que o Brasil está inserido desde os Jogos Pan-Americanos de 2007 tem fomentado discussões no cenário acadêmico e midiático relacionadas, entre outros temas, aos modelos de formação esportiva nacional, às aplicações e eficácia das leis de incentivo ao esporte, às estratégias para descoberta de novos talentos, às condições físicas das praças esportivas e à constituição dos legados originários desses megaeventos.

Quanto à formação esportiva, as discussões se acentuam em temas que problematizam periodizações de treinamentos, especialização precoce em jovens atletas, questões psicológicas aplicadas ao esporte e às questões pertinentes ao doping. Entretanto, observamos que a organização de estratégias voltadas à conciliação entre as formações esportiva e escolar para jovens atletas envolvidos nessa "dupla carreira" tem sido um tema em que há a necessidade de proporcionar maior visibilidade.

Nesse contexto, identificar como, em diferentes países, ocorre a formação esportiva concomitante à escolar nos possibilitaria projetar ações de conciliação ${ }^{1}$ entre elas que não comprometessem a aquisição do capital cultural institucionalizado ${ }^{2}$, levando-se em conta 0 fato de ele ser reconvertido futuramente em capital econômico.

Assim, este artigo procura compreender, por meio das produções acadêmicas nacionais e internacionais, quais são as estratégias de conciliação apresentadas entre as formações escolar e esportiva em diferentes modalidades.

A fim de que se aponte como os estudos relativos à temática se apresentam na literatura de nossa área, assumimos, no referencial teórico-metodológico, as orientações relativas a pesquisas que tratam o periódico como fonte. Mostramos ainda o caminho percorrido para a seleção dos artigos e posteriormente analisamos o mapeamento realizado por meio de indicadores bibliométricos. ${ }^{3}$

\section{MÉTODO}

Pesquisas do tipo "estado do conhecimento" são desenvolvidas por serem capazes de apontar a distribuição da produção acadêmica a respeito de um tema, por meio de conexões estabelecidas entre elementos contextuais e um conjunto de outras variáveis, como data de publicação, temas e periódicos (MOROSINI et al., 2002, ANDRÉ, 2009; MATOS et al., 2013).

Por outro lado, assumimos a limitação de pesquisas desse tipo devido a algumas questões, como critérios e fonte utilizados em virtude do variado formato dos resumos utilizados em teses e dissertações, títulos de trabalho difusos e acesso ao material da pesquisa que pode tornar-se dispendioso e demorado (ROMANOWSKI; ENS, 2006).

Este estudo se constitui como integrante de um projeto maior denominado "Escolarização e Esportes", que se iniciou em 2007, pesquisando as características particulares do futebol (SOARES; BARTHOLO, 2009; MELO, 2010; BARTHOLO et al., 2011; ROCHA et

\footnotetext{
1 Toma-se por empréstimo o estudo de Costa (2012) para conceituar essa ideia, apresentando o termo "conciliação" como a proposição que tenta equilibrar os tempos escolares e de treinamentos. 
al., 2011; BARRETO, 2012). Posteriormente, o grupo de pesquisadores avançou na direção de outras modalidades, ${ }^{4}$ aumentando as chances de entendimento da questão de interesse também em outros ambientes esportivos. Nesse contexto, percebemos que nenhum desses estudos tinha como amostra atletas de elite envolvidos com o basquetebol nos desafiando a investigar melhor as particularidades do tema também relacionadas a uma nova modalidade.

Assim, estabelecemos como parâmetro de busca na pesquisa nacional o termo basquetebol. Como não encontramos trabalhos que discutiam o tema, ampliamos para descritores que nos remetessem às relações entre formação esportiva e escolar, como "escolarização x atleta", "esporte x escolarização", "formação esportiva x escolarização", "estudantes atletas x escolarização" e "basquetebol x escolarização". A opção pelo uso desses descritores permitiu-nos uma ampliação do sistema de busca, bem como da constituição do corpus documental da pesquisa, publicada em fontes nacionais e internacionais. A seleção dos textos foi delimitada por uma leitura prévia do título dos artigos e dos resumos e, em um segundo momento, dos textos na íntegra.

Utilizamos como fonte a plataforma de pesquisa SciELO Brasil e outros periódicos não indexados à plataforma, mas de considerável circulação na área da Educação Física brasileira. Assim, foram encontrados inicialmente 45 artigos nacionais relacionados com esses descritores nas revistas indexadas ao SciELO, além das revistas Movimento, Pensar a Prática e Atividade Física e Saúde. Após leitura na íntegra dos textos, esse universo foi reduzido a dois trabalhos.

Em relação à literatura publicada em fontes internacionais, a pesquisa se organizou mediante busca no Portal Periódicos Capes, levando em consideração tanto a área de conhecimento das Ciências da Saúde como a de Ciências Humanas. O portal nos proporcionava a seleção de, no máximo, 11 bases de dados que foram selecionadas depois de observadas as descrições oferecidas pelo próprio portal.

Esse processo de seleção de artigos foi conduzido, em um primeiro momento, por dois pesquisadores, que selecionaram, nas duas grandes áreas de conhecimento escolhidas, as bases de dados a seguir: Journals@ovid Full Text (Ovid), Psyarticles (APA), Science (AAAS), Scielo.org, Science Direct (Elsevier), Scopus (Elsevier), Springerlink (Metapres), Academic Search Premiere Asp (Ebsco), Eric (Proquest), Cambridge Journal on-line, Wiley on-line Library. Para tanto, utilizamos os seguintes descritores e combinações, visando a atender às demandas de formação escolar, esportiva e os respectivos atores: students athletes/education (21 artigos), Youth athletes/education (um artigo), youth athletes/schooling (nenhum artigo), sports education/athletes (13 artigos), professional sports/family (um artigo), professional sports/education (15 artigos), youth talent/sports (cinco artigos), Sports talent/ education (um artigo), young players/education (cinco artigos), young students/education (49 artigos) e young students/schooling (oito artigos).

Das possibilidades de refinamento oferecidas pelo portal, adotamos "título" como filtro, o que proporcionou 119 artigos. Após leitura, reduzimos, em virtude da temática, o universo para 15 artigos internacionais.

\footnotetext{
4 A pesquisa a respeito do tema Escolarização e esporte surge no Brasil em 2007. Bartholo e Soares (2009) e Melo (2010) apresentam trabalhos ligados ao futebol. A seguir, Romão, Costa e Soares (2011) e Soares, Rocha e Costa (2011) estudam voleibol e turfe, respectivamente. A modalidade futebol volta a ser apresentada em Rocha et al. (2011) e Barreto (2012). Por sua vez, Costa (2012) apresenta seu estudo em relação ao futsal feminino.
} 


\section{RESULTADOS}

Mapeamos 17 artigos científicos, distribuídos em 13 diferentes periódicos, dos quais 11 internacionais e dois nacionais. Os artigos localizados foram publicados no período compreendido entre 1979 e 2011, conforme apresentamos a seguir.

Sack e Thiel (1979) foi o estudo mais antigo encontrado por meio dos descritores utilizados, seguidos de Lee (1983), Sack (1987) e Goldberg e Chandler (1995). Esses estudos estadunidenses anteriores a 2000 representam $23,5 \%$ da produção selecionada e foram publicados em diferentes periódicos, reforçando o pioneirismo dos americanos em relação à preocupação com o tema e o importante valor que o esporte e a educação assumem na sociedade e cultura daquele país.

Além disso, outro fator que pode explicar essa preocupação é que verificamos que, desde a década de 1970, há um incremento das ligas profissionais esportivas americanas, abastecidas, em sua grande maioria, por atletas vindos das universidades. 0 surgimento de grandes ídolos esportivos e o crescimento das ligas contribuíram para se evidenciar a necessidade de criar estratégias que proporcionassem aos estudantes-atletas acesso às formações escolar e esportiva com reduzido prejuízo entre elas, já que muitos deles passaram a considerar essa possibilidade de profissionalização esportiva, conforme nos mostra Lee (1983).

A partir do ano 2000, o número de artigos aumenta, chegando a 13 publicações (ou $76,5 \%$ das fontes), culminando em 2011, quando são observadas três publicações ligadas ao tema, das quais duas brasileiras, e abordando o futebol como modalidade estudada. Esse aumento no número de produções talvez seja explicado pelas dimensões que 0 esporte, entendido como um fenômeno cultural, passa a assumir nas mais diferentes localidades, nos valores financeiros envolvidos, nos megaeventos realizados e na velocidade de surgimento de ídolos mundiais nas mais variadas modalidades.

Com relação à produção nacional, os estudos citados foram publicados na revista Motriz e na Revista Brasileira de Ciências do Esporte e são oriundos do Laboratório de Pesquisa em Educação do Corpo (Labec), coordenados pelo professor Antônio Jorge Soares.

Os periódicos que mais publicaram sobre o tema foram o Journal of Sports and Social Issues e o European Physical Education Review. três artigos cada um, perfazendo 35,3\%. No primeiro periódico, os estudos datam de 1987 (1) e 2003 (2); já no segundo, os trabalhos são publicados em 2000, 2002, 2009.

Ainda por meio dos artigos e periódicos, analisamos a distribuição da produção a respeito do tema em diferentes países. Os Estados Unidos lideram esse cenário de publicações (SACK; THIEL, 1979; LEE, 1983; SACK, 1987; GOLDBERG; CHANDLER, 1995; SINGER; MAY, 2011) com cinco trabalhos. Parker (2000), Kay (2000) e Collins e Buller (2003) colocam o Reino Unido no cenário de pesquisas desse tema. A Dinamarca aparece posteriormente com dois artigos, Christensen e Sorensen (2009) e Agergaard e Sorensen (2009). Da Finlândia, identificamos o trabalho de Metsa-Tokila (2002). Bourke (2003) produz seus estudos na Irlanda; Hickey e Kelly (2008), na Austrália; Barros (2001), em Portugal; e McGillivray e Mcintosh (2006), na Escócia. No Brasil, identificamos os trabalhos de Rocha et al. (2011) e Soares et al. (2011). Vale salientar que não os assumimos como únicos produtores de estudos a respeito do tema 
e que reconhecemos as limitações anteriormente descritas, diante dos critérios estabelecidos para a pesquisa.

Em relação aos autores, Sack, professor ligado ao Departamento de Sociologia da Universidade de New Haven (EUA), foi responsável por dois dos quatro artigos apresentadas antes de 2000, pesquisando características de estudantes-atletas americanos. Sorensen (2009a, 2009b), pesquisador ligado ao Departamento de Ciências do Esporte da Universidade de Aarhus da Dinamarca, e Soares (2011, 2011b), professor do Programa de Pós-Graduação em Educação da UFRJ (Brasil), destacam-se após 2000, ambos com dois estudos publicados. As pesquisas do dinamarquês são divulgadas na Soccer and Society, da Inglaterra, e na European Physical Education Rewiew. As pesquisas de Soares são veiculadas nos periódicos brasileiros Motriz e Revista Brasileira de Ciências do Esporte, em 2011.

\section{DISCUSSÃO}

O acúmulo de leituras a respeito do tema conduziu-nos a pesquisas publicadas em periódicos, que representam estudos de diferentes modalidades esportivas em relação à temática em questão. Eles apresentam diferentes características relativas às tensões vividas por estudantes-atletas, tornando-os relevantes para enriquecer 0 debate relativo às tentativas de conciliação entre a formação esportiva e a escolar de jovens estudantes-atletas.

Nesse contexto, levamos em consideração desde essa etapa, para enriquecer nossa discussão a respeito do tema, nove artigos não localizados nas fontes de dados selecionadas, tais como uma tese de doutorado (COSTA, 2012), dissertações de mestrado (MELO, 2010; BARRETO, 2012; ROCHA, 2013; CORREIA, 2014) e estudos apresentados em congressos (BARTHOLO et al., 2011; SOARES; ROCHA; COSTA, 2011, ROMÃO; COSTA; SOARES, 2011), além de três artigos publicados em um número especial do periódico New Directions for Students Services, de 2001.

Levando em consideração o conteúdo dos artigos, os subdividimos em três eixos de análise. Por esses eixos foi possivvel apresentar as diferentes abordagens que nos levarão às principais preocupações apontadas pelos autores nos artigos pesquisados, a saber: tensões presentes na conciliação das formações esportiva e escolar; tentativas de conciliação e particularidades entre as formações; e a influência da família em relação à formação escolar e esportiva.

\subsection{Indícios conflituosos e tensões relativas à formação esportiva e escolar de estudantes atletas}

A simultaneidade das formações escolar e esportiva tem acarretado um ambiente de tensão entre elas porque demandam grande dedicação de tempo. Como nos mostra Lee (1983), muitos estudantes-atletas estão considerando as carreiras esportivas em uma perspectiva profissional influenciados pelo aumento da exposição na mídia das modalidades esportivas e incentivados pelo status econômico oferecido àqueles que conseguem êxito nessa proposta.

A questão nesse sentido é que poucos estudantes-atletas conseguirão profissionalizarse no esporte e, assim, a grande maioria ficaria exposta a dificuldades de posterior inserção no mercado de trabalho ordinário, sendo esta uma questão recorrente nos estudos brasileiros e 
norte-americanos. Segundo pesquisas da NCAA, ${ }^{5}$ a porcentagem de aproveitamento de atletas universitários em ligas esportivas profissionais americanas chega a 1,2\% no basquetebol masculino e $0,9 \%$ no basquetebol feminino. A maior probabilidade de profissionalização esportiva para estudantes-atletas americanos está na modalidade beisebol, com um aproveitamento de $9,4 \%$. Todas as outras modalidades acompanhadas e pesquisadas pela NCAA (futebol americano, hóquei no gelo e futebol masculino) apresentam porcentagens de aproveitamento abaixo de $2 \%$. Essa dificuldade é demonstrada em estudos nacionais quando Proni (2000) e Damo (2005) apresentam o cenário limitado de postos de trabalho, sazonalidade e baixos salários na modalidade mais representativa economicamente do mercado esportivo: 0 futebol; ou quando Romão, Costa e Soares (2011), no vôlei e Costa (2012), no futsal feminino, e Romão, Costa e Soares (2012), no vôlei ${ }^{6}$ abordam o nível de dedicação dos atletas que entendem os limites do mercado esportivo em que estão inseridos.

Assim, ratifica-se a preocupação de que, se porventura os estudantes-atletas apresentarem formações acadêmicas deficientes, poderão enfrentar uma difícil transição para o mercado de trabalho formal, uma vez que suas credenciais esportivas não representarão qualificação em um mercado que exige outros tipos de formação (METSA-TOKILA, 2002). Não podemos desconsiderar, com base nesses dados, o modo como a formação esportiva está organizada nos Estados Unidos. Vemos, nesse caso, uma formação que acontece dentro do espaço escolar, por meio de atividades extracurriculares que atravessam o elementary, middle e o high school, ${ }^{7}$ bem como a universidade.

Se tomarmos como exemplo o basquetebol, para se ter direito à profissionalização esportiva por meio da Associação Nacional de Basquetebol (NBA), o atleta americano deve ter no mínimo 19 anos e um ano de conclusão do high school. Esse movimento evidencia tensões entre a NBA e a NCAA, bem como entre as formações esportiva e escolar, pois os atletas podem inserir-se nas universidades para jogar um ano na NCAA e, no próximo ano, ser levados para a NBA, sem que precisem concluir as respectivas formações acadêmicas.

Isso significa ressaltar que o "sonho da profissionalização esportiva" tem apresentado também como resultado uma iniciação esportiva cada vez mais precoce, acarretando aumento na concorrência de tempo entre essa formação e a formação escolar. Bartholo et al. (2011), em estudo referente ao tempo destinado à escola e ao futebol na Espanha e no Brasil, constataram que a destinação de tempo à prática esportiva no Brasil corresponde a $52 \%$ das atividades de jovens entre 14 e 20 anos, enquanto no país europeu esse tempo é de $27 \%$, o que sugeriria, na visão dos autores, uma inversão de prioridades no Brasil.

Damo (2005) e Melo (2010) apontam em suas pesquisas a destinação de tempo de aspirantes a futebolistas nacionais em dois grandes centros: Rio Grande do Sul e Rio de Janeiro. Em ambos os casos, foi constatado que um atleta que inicia sua trajetória esportiva na categoria mirim aos 12 anos de idade (idade equivalente ao 6ํano escolar) e termina no ensino médio aos 17 anos (último ano da categoria Sub 17) terá sido submetido a uma carga horária de 4.800 horas na escola e a mais de 4.150 horas de treinamento no futebol.

A escolha do Brasil como sede de megaeventos esportivos nos próximos anos pode contribuir para que também sejam pensadas em nosso país novas estratégias que atenuem

5 A National College Athletics Association é a maior associação regulamentadora de esporte universitário dos Estados Unidos. 6 ROMÃO, Marcio Gabriel; COSTA, Felipe Rodrigues da; SOARES, Antonio Jorge Gonçalves. Escolarização de equipes do voleibol no Rio De Janeiro. Trabalho apresentado no XI Congresso Espírito-Santense de Educação Física, Vitória, 2011.

7 Refere-se ao ensino elementar, médio e secundário. 
os conflitos entre as formações. Essa possibilidade de rendimento esportivo condicionado a um rendimento escolar começa a ser percebida, por exemplo, no projeto de implantação do Ginásio Esportivo Olímpico (GEO), em Santa Teresa, Rio de Janeiro.

Fato é que ganha força a tendência, colocada desde a década de 1970, de valorizar em níveis governamentais a escola como local de descoberta de novas "promessas" do esporte e consequente revalorização de desporto escolar. Recentemente, a exemplo, foi lançado no País, pelo Governo Federal, o programa "Atleta na Escola", ${ }^{8}$ que apresenta como um dos objetivos a ênfase na descoberta de talentos no ambiente escolar que, na expectativa da lei, contribuiriam para um bom desempenho do País nos Jogos Olímpicos RIO 2016.

A elaboração de programas com essas características tem suas inspirações no modelo norte-americano de formação. Em uma análise inicial, observamos que a definição do espaço escolar como ambiente de desenvolvimento esportivo surgiria como uma possibilidade de melhor distribuição dos tempos destinados à formação esportiva e escolar e como um estímulo para que fossem diminuídas as dificuldades de comunicação entre os dois ambientes formadores atuais, a saber, clube e escola, contribuindo para que se diminuísse o comprometimento de uma em detrimento da outra.

Contudo, a implementação de um sistema de formação esportivo oferecido e alinhado com a formação escolar está longe de ser uma garantia para resolver os problemas da conciliação. Correia (2014), ao analisar esse processo no Colégio Vasco da Gama, evidencia as tensões presentes na dedicação dos atletas na "dupla carreira", como, por exemplo, os ajustes realizados para melhorar as condições e tempos de dedicação ao treinamento, que colocam sempre em primeiro plano a formação esportiva, secundarizando a escolar. Ou seja, os projetos de formação, mesmo em instituições destinadas ao atendimento aos atletas, encontram-se em concorrência. É por isso que, de maneira geral, os autores estudados reconhecem as tensões existentes para os envolvidos nessa "dupla carreira" e ressaltam a importância de proporcionar condições para que esses jovens tenham acesso a uma formação integral, visto que suas credenciais acadêmicas se tornam indispensáveis para a inserção em mercados de trabalho formais, em caso de insucesso na carreira esportiva.

\subsection{Tentativas de conciliação entre as formações}

Uma análise dos textos nos permite evidenciar as tentativas realizadas por diferentes países em conciliar a formação esportiva e escolar. Notamos que, em países como a Dinamarca, a Suécia, a Finlândia e na antiga União Soviética, a condição estudante/atleta foi assumida como uma preocupação estatal, tentando organizar a questão para que os jovens envolvidos na "dupla carreira" não fossem prejudicados em suas formações esportivas e acadêmicas (METSA-TOKILA, 2002). Nos Estados Unidos, essa tentativa de conciliação ocorreu por meio de órgãos fiscalizadores de desempenhos escolares dos estudantes-atletas envolvidos e diretamente ligados às escolas e universidades.

Na Suécia, a busca da conciliação se deu inserindo a formação esportiva no ensino secundário, sem distinção de turmas entre não atletas e atletas, com oferta pela escola de suporte para que realizem seus treinamentos supervisionados por um treinador qualificado,

8 Disponível em:<http://portal.mec.gov.br/index.php?option=com_content\&view=article\&id=18644:tres-ministerios-lancam-programa-paraestimular-o-esporte-nas-escolas\&catid=211>. Acesso em: 15 out. 2013. 
estimulando, assim, a convivência entre estudantes-atletas e não atletas e proporcionandoIhes condições, no interior da escola, para que desenvolvam suas habilidades atléticas.

Na Finlândia, em 1970, iniciou-se um projeto para combinar o esporte de rendimento com um currículo escolar flexibilizado para os jovens atletas, fazendo com que fosse alongado 0 tempo da formação na escola secundária. A tentativa de estender o tempo de formação acadêmica partia do princípio de que as necessidades do esporte não permitiam o acompanhamento e dedicação aos estudos com a mesma intensidade que dos outros não atletas. Se a carga de aulas e estudo fosse mais bem distribuída, isso em tese poderia fazer com que os atletas tivessem acesso a uma formação acadêmica com qualidade semelhante à dos não atletas. Se a princípio parecia coerente, a efetiva implantação desses projetos encontrou dificuldades ao longo do tempo, ligadas a políticas governamentais, ao custeio ou à cultura das próprias escolas. Como exemplos dessas dificuldades, podemos citar a adaptação dos currículos para atender aos atletas, a distribuição deles ao longo de mais um ano de formação secundária e o convencimento da classe de professores e de algumas famílias a esse favor, para que se modificasse uma lógica escolar.

Já na Dinamarca, em escolas que funcionariam também como centros de treinamento, houve tentativa de flexibilizar o currículo escolar, buscando proporcionar aos atletas de elite menos tempo de aulas por dia e mais horas destinadas aos treinamentos, além de abono de faltas e reposição de provas, se o aluno tivesse a situação de conflito com datas de jogos. A grande dificuldade enfrentada nessa estratégia foi que poucas escolas, em poucas cidades, estavam preparadas para oferecer ao aluno essas possibilidades, além de muitos alunos precisarem deslocar-se diariamente ou então se mudar para as escolas (cidades) que ofereciam essa possibilidade de treinamento e escolarização unificadas (AGERGAAD, SORENSEN, 2009; CHRISTENSEN; SORENSEN, 2009).

No Brasil, tem-se notado, talvez pelo momento pré-olímpico, um aumento da atenção, em níveis governamentais, à questão de estratégias que poderiam direta ou indiretamente contribuir nas questões de conciliação entre as formações. Todavia, as principais iniciativas ainda surgem principalmente das partes envolvidas nos processos de flexibilização de estudo - famílias, estudantes-atletas, clubes e escolas - com a finalidade principal de proporcionar a permanência do aluno na escola.

Nesse sentido, Melo (2010) apresenta algumas maneiras de conciliação presentes no futebol. Entendemos ser preciso que essas propostas se relativizem em virtude de diferentes amostras utilizadas no estudo; todavia, servem para nos indicar algumas estratégias. Uma delas é a possível migração de estudantes-atletas para o ensino noturno, à medida que vão ascendendo de categoria, para que não coincidam os horários de treinamento com os da escola, e o "atraso sistemático" caracterizado por permitir a um atleta que, por meio de um acordo clube/escola, chegasse à escola com 30 minutos de atraso diariamente, sem que fosse institucionalmente prejudicado por isso.

Outra estratégia apontada foi o caso de um clube, no estado do Rio de Janeiro, que adotava, à época da pesquisa, o regime de "albergamento", em que o atleta residia e estudava nas dependências do clube. Embora, nesse tipo de regime, o estudante-atleta se beneficiasse de poder assistir às aulas em turnos diferentes no interior do próprio clube, de acordo com os seus compromissos esportivos, otimizando o tempo por descartar os períodos gastos com deslocamentos até a instituição escolar, apresentamos algumas ressalvas referentes à 
estratégia. Entendemos que, apesar de essas questões de otimização, sob o aspecto funcional, serem importantes, algumas características particulares confrontam a lógica organizacional escolar, como ausência de turma e turno fixos para esse aluno, e a descontinuidade na relação professor/aluno em virtude dos variados horários de presença nas aulas. Essas particularidades precisariam ser mais bem analisadas quanto aos impactos causados na relação ensinoaprendizagem e na valorização da escola nesse cenário.

Barreto (2012) mostra que o albergamento também é utilizado em uma equipe mineira de futebol, denominando-o como um oferecimento direto de acesso à escolarização. Assim, essa equipe oferece, por meio de um convênio com uma escola particular de Belo Horizonte, opção de acesso à escolarização para seus atletas no interior da "Toca da Raposa l". Embora chamemos a atenção para as mesmas ressalvas citadas, concordamos com Barreto (2012), ao analisar essa relação de parceria como benéfica para dois dos envolvidos nessa estratégia de conciliação, já que, para os clubes, tanto o mineiro quanto o carioca, o acesso à escolarização dos atletas passa a não intervir nos horários de treinamentos deles e, para a escola, como instituição particular de ensino, o número satisfatório de matrículas anuais corrobora as expectativas em relação ao ensino oferecido pelos clubes. Só ainda não foi possível quantificar o impacto dessas adaptações no tocante ao acúmulo de capital cultural institucionalizado por parte dos estudantes-atletas.

Outra equipe mineira, mesmo apresentando um regime de albergamento para seus atletas em idade escolar, utiliza-se de escolas da rede de ensino municipal e estadual para que seus atletas tenham acesso a essa formação. A equipe fica responsável pela matrícula do aluno, transporte de ida e volta à escola e segurança no trajeto Centro de Treinamento/Escola/ Centro de Treinamento. Essa estratégia é vista pelo autor como um oferecimento indireto de acesso à escolarização (BARRETO, 2012).

Ainda no caso dessa segunda equipe mineira, vem sendo adotada a matrícula no Centro Estadual de Educação Continuada (Cesec) - programa de ensino instituído pelo Governo Estadual de Minas Gerais destinado a atender à grande demanda de alunos com histórico de evasão ou exclusão escolar, inclusive aqueles que não conseguiram concluir o ensino supletivo. A adoção desse modelo, por parte de um clube de futebol em relação aos seus atletas em formação, evidencia a realidade do jovem estudante em conciliação com 0 trabalho.

Salientamos que as estratégias de oferecimento de acesso à escolarização vistas nas duas equipes mineiras, apesar de distintas, avançam para além de serem uma justificativa social para o convencimento de pais de jovens talentos esportivos futebolísticos. Essas estratégias não permitem que seus atletas em formação fiquem sem acesso aos conteúdos formais escolares e, ao mesmo tempo, impedem que esse acesso à formação escolar afete os horários e a qualidade dos treinamentos no futebol. Então, cada um à sua maneira procura alternativas e soluções que melhor atendam a esse processo de conciliação de formações do qual o clube, queira ou não, é integrante.

Analisando o futsal feminino catarinense, a conciliação entre o esporte e a escola surge como uma maneira de alcançar credenciais acadêmicas universitárias por parte das atletas que já finalizaram o ensino médio, utilizando bolsas de estudo nas universidades apoiadoras dos projetos esportivos (COSTA, 2012). Essas bolsas são oferecidas como contrapartida em forma de "salário indireto" para que as atletas disputem os campeonatos por determinadas 
instituições de ensino, agregando valor ao seu salário, já que "gastariam menos" por sua formação acadêmica. $O$ contexto analisado permite inferir que, ao contrário do futebol, as jovens atletas de futsal em Santa Catarina participam de um cenário esportivo com mercado reduzido, sobretudo quanto à remuneração, e entendem a formação escolar como fundamental para inserção no mercado de trabalho num futuro próximo (COSTA, 2012). Foi percebido, portanto, maior equilíbrio entre os tempos de formação, implicando ainda melhor adequação dos horários de treinos aos horários escolares - principalmente às estudantes do ensino fundamental e médio.

Uma análise das experiências de conciliação realizadas por diferentes países nos sinaliza, pelo menos, três formas utilizadas para tratar o tema: a) a que privilegia a formação esportiva; b) a que privilegia a formação escolar; c) a que objetiva produzir uma conciliação mantendo o equilíbrio entre a escolar e a esportiva. Isso não significa que algum país desvalorize a formação escolar, mas, em suas formas de conciliação, essas experiências revelam os sentidos/valores diferentes para ela.

Entendemos que as intencionalidades produzidas na Dinamarca e no Brasil privilegiam a formação esportiva com diminuição de tempo de aula, abono de faltas, reposição de provas e matrícula no ensino noturno. Uma tentativa de minimizar os problemas da conciliação está na implementação de albergamentos realizados, por exemplo, por clubes como de Minas Gerais e do Rio de Janeiro. Encontramos, nesse caso, a formação escolar oferecida pelo clube ou oportunizada por ele nas redes de ensino pública ou privada.

Temos uma diferenciação importante quando se analisam os achados das pesquisas realizadas no Brasil e as que falam das experiências dos Estados Unidos e da Suécia. Em ambos os países, as experiências de formação esportiva são feitas no contexto escolar, e não no contexto clubístico. $O$ fato de ser realizada na escola facilita a organização dos tempos e do currículo escolar. Não estamos, com isso, defendendo a esportivização da Educação Física escolar para a formação de atletas, embora, nos Estados Unidos, esse movimento seja realizado em atividades extracurriculares, mas objetivamos mostrar as saídas encontradas pelos países para que se mantenha um equilíbrio na conciliação.

Por fim, temos a experiência da Finlândia, que organizou sua flexibilização com 0 intuito de potencializar a formação escolar, ampliando a escolarização por mais um ano no ensino secundário para os estudantes-atletas.

As experiências evidenciadas pelos autores dos diferentes países mostram a complexidade do tema e a sua relevância, já que encontramos várias sociedades preocupadas com a conciliação e suas implicações para o futuro dos jovens.

\subsection{Família, escola e formação escolar e esportiva}

Neste terceiro momento, abordamos a relação da família e da escola no que diz respeito à priorização da formação esportiva. Esse assunto é focalizado por Lee (1983), Goldberg e Chandler (1995), Kay (2000), Collins e Buller (2003), Soares et al. (2011), Rocha et al. (2011), Soares, Rocha e Costa (2011), Singer e May (2011), Romão, Costa e Soares (2011), Costa (2012), Barreto (2012) e Rocha (2013), o que representa quase $45 \%$ dos trabalhos considerados. 
Kay (2000) considera o ambiente familiar como importante fator na formação do jovem esportista, principalmente se os pais forem adeptos de suas modalidades, seja no âmbito de rendimento, seja no do lazer. Aspectos ligados a uma condição econômica estável, em nível de formação acadêmica dos pais, e à presença do pai e da mãe em casa, também se apresentam como diferenciais na formação esportiva dos jovens e no valor que atribuem à formação escolar.

Não verificamos no estudo preocupação em traçar relações referentes ao papel do tempo destinado à formação esportiva em comparação com o desempenho escolar, porém 0 autor permanece atento à seletividade social do esporte, em que jovens pertencentes a famílias de classes sociais menos favorecidas podem ter seu acesso aos ambientes esportivos limitados. Esse fator contribuiria para que o desenvolvimento de suas habilidades esportivas fosse prejudicado. Essa questão também é apontada por Collins e Buller (2003) em relação às desigualdades de acesso ao esporte por jovens de diferentes classes sociais da Inglaterra.

No Brasil, encontramos pesquisas que discutem sobre as implicações das questões familiares no processo de conciliação esportiva e escolar. No turfe, embora o que dificulte a conciliação entre escolarização e esporte seja a baixa frequência e, consequentemente, a baixa quantidade de horas de permanência na escola em virtude das competições semanais (às segundas e às sextas), também se evidencia o impacto do pertencimento de classe desses jovens em relação ao pouco investimento escolar (SOARES; ROCHA; COSTA, 2011). $O$ estudo reforça a relação econômica estabelecida com o esporte ainda no processo de formação, mostrando que, para esses jovens, o ganho inicial nos páreos é motivo de dedicação às exigências do processo de formação no jóquei, mesmo que isso signifique perder 0 ano escolar.

No voleibol carioca (ROMÃO; COSTA; SOARES, 2011) e no futsal feminino (COSTA, 2012), a principal característica da importância atribuída à conciliação esporte/escola acontece principalmente em virtude do background familiar, que é entendido como a relação de características sociais e intelectuais da família da qual o jovem faz parte.

O futsal feminino em Santa Catarina (COSTA, 2012) apresenta uma característica de média de formação acadêmica dos pais das atletas envolvidos maior do que as médias de escolarização nacional. Essa característica exerce influência na importância atribuída aos estudos por seus filhos, resultando, nesses adolescentes envolvidos em modalidades de quadra, em um melhor entendimento da necessidade de continuar seus estudos mesmo praticando esportes.

Em nosso modo de entender, fica evidente o papel da família como determinante na escolha das importâncias atribuídas às formações esportiva e escolar. Ela é capaz de determinar, por meio do nível de escolarização dos pais, por exemplo, a questão da priorização atribuída às demandas escolares e esportivas. Além disso, pode impactar na medida em que a aposta esportiva de um estudante atleta passe a se tornar a aposta esportiva de toda a família que, nesse caso, não mediria esforços para que essa difícil missão de profissionalização no esporte se concretizasse para que todos possam posteriormente desfrutar de suas benesses financeiras.

Contudo, não podemos atribuir apenas à família a responsabilidade pela conciliação entre a formação esportiva e a escolar. Essa é uma questão de interesse do Estado, que precisa criar políticas de formação para esses jovens, e do próprio clube, que necessita oferecer 
condições para que os estudantes-atletas tenham formação escolar com qualidade. Temos ainda que pôr na centralidade do debate o valor atribuído pelos jovens à formação escolar, sobretudo quando encontram no esporte uma possibilidade de profissionalização.

\section{APONTAMENTOS FINAIS}

Por meio das pesquisas às quais tivemos acesso durante este estudo, pudemos verificar a relevância do tema em relação ao futuro dos estudantes-atletas e algumas variáveis que influenciam o sucesso desse jovem. Notamos que essa temática vem sendo abordada nos Estados Unidos há aproximadamente 30 anos antes de começar a ser estudada no Brasil, onde, por meio de pesquisas do Labec, o tema surge em 2007, com sua primeira publicação localizada em periódicos em 2011. É notada também uma predominância inicial de autores e periódicos estadunidenses que talvez seja explicada principalmente pela valorização atribuída às dimensões educacionais e esportivas na cultura daquele país. Outros fatores que podem explicar tal condição são o modelo de formação esportiva escolar adotado e o incremento das ligas profissionais esportivas americanas. Esse incremento contribuiu para despertar em estudantes-atletas americanos o desejo de se profissionalizarem, gerando certa tensão entre esses ambientes. Como contramedidas, surgiram associações regulamentadoras que regem as relações entre escola e esporte com importantes condicionantes.

Também foram localizados estudos abordando o tema oriundos de países europeus, tais como a Suécia, a Finlândia, a Dinamarca, a Irlanda e a antiga União Soviética, com a similaridade de apresentar suas formações esportivas no ambiente escolar e de mostrar o futebol como a modalidade com maior número de produções. Talvez o predomínio da modalidade em estudos se justifique pelo apelo financeiro que apresenta para os praticantes que alcançam êxito nessa proposta ao redor do mundo. Todavia, as tentativas de conciliação entre as formações, diferentemente das encontradas nos Estados Unidos, surgem de iniciativas estatais, reflexo de pressões exercidas pelas sociedades locais. É interessante notar que, apesar das preocupações do Estado e da sociedade, os estudantes-atletas com maior potencial e resultados esportivos, a princípio, demonstravam maior interesse na formação esportiva. $A$ expectativa de sucesso profissional ainda jovem colabora para a percepção da escola como um tempo-espaço que "atrapalharia", no caso, sua formação e projeção esportiva.

A análise bibliométrica aponta que, além dos Estados Unidos, estudos estão sendo desenvolvidos na Europa, sobretudo na Dinamarca, por pesquisadores da área do esporte. $\mathrm{Na}$ América Latina desponta o Brasil com um grupo de estudos que aborda a temática no âmbito da pós-graduação (mestrado e doutorado), além de promover o debate com seminários e publicações em periódicos científicos. A produção brasileira também apresenta uma variedade maior de modalidades investigadas, como futebol, voleibol, basquetebol, turfe e futsal.

Diante dos resultados encontrados, parece-nos que, em um país com importantes diferenças sociais como o Brasil, o jovem que alcança sucesso esportivo, e decide apostar neste campo profissional, poderá ter sua formação escolar prejudicada ou interrompida. Caso isso aconteça e sua carreira esportiva não alcance os resultados financeiros esperados, sua inserção no mercado de trabalho formal será comprometida, pois suas credenciais acadêmicas são baixas. Percebemos que os atletas tomam essa decisão perto dos 16, 17 anos, o que permitiria que chegassem ao ensino médio. 
A formação esportiva conciliada à formação escolar, como acontece nos Estados Unidos, adequada ao contexto brasileiro, precisa ser discutida e formatada. É fundamental a compreensão de órgãos governamentais, entidades esportivas, clubes e família de que 0 mercado esportivo não irá atender todo o contingente em formação, e que os postos de trabalho que rendem status e contratos milionários são escassos e, no Brasil, limitam-se basicamente ao futebol.

Nesse contexto, conforme percebido, identificar estratégias que possibilitem melhor equilíbrio temporal entre essas formações significa uma possibilidade de oferta de uma trajetória escolar-esportiva mais condizente com a necessidade desses estudantes-atletas, sem detrimento de uma pela outra, favorecendo, ao longo dessa trajetória, a obtenção de um capital cultural institucionalizado de qualidade. Como vimos, existe a tentativa de atrelar a ascensão esportiva ao rendimento mínimo escolar e a flexibilização do currículo para que o aluno-atleta tenha a possibilidade de equilibrar os tempos de formação. Importante destacar que existem agências, estatais ou não, que fiscalizam esse processo e cobram das instituições esportivas o cumprimento das normas estabelecidas. No Brasil, a formação clubística está distanciada da formação escolar, não existe a possibilidade de flexibilização do currículo, as negociações estabelecidas entre clube e escola são determinadas pelo sonho em seguir a carreira esportiva e pelos contratos milionários.

Além disso, é preciso, em estudos futuros, discutir sobre o tempo dedicado para a formação esportiva e o que se faz com ele, já que, para pensarmos na conciliação das formações temos também que discutir sobre a qualidade do processo de formação esportiva no Brasil. Como ocorre o processo de periodização da formação, quando pensamos a distribuição dos treinamentos oferecidos em cada categoria esportiva? Na busca por uma especialização precoce, não estamos atribuindo uma sobrecarga de treinamento, nas diferentes categorias, que demanda cada vez mais tempo de dedicação? São questões a responder em um próximo estudo.

\section{REFERÊNCIAS}

ANDRÉ, Marli. A produção acadêmica sobre formação de professores: um estudo comparativo das dissertações e teses defendidas nos anos 1990 e 2000. Formação Docente: Revista Brasileira de Pesquisa sobre Formação Docente, v. 1, n. 1, p. 41-56, ago./dez. 2009.

AGERGAARD Sine; SØRENSEN, Jan Kahr. The dream of social mobility: ethnic minority players in Danish football clubs. Soccer and Society, v. 10, n. 6, p. 766-780, 2009.

BARRETO, Paulo Henrique Guilhermino. Flexibilização escolar para atletas em formação alojados em centros de treinamento no futebol: um estudo na Toca da Raposa e na Cidade do Galo. 2012. 106 f. Dissertação (Mestrado em Educação Física) - Programa de PósGraduação em Educação Física, Universidade Federal do Espírito Santo, Vitória, 2012.

BARROS, Carlos Pestana. Economic return on schooling for soccer players. Journal of Sports Economics, v. 2, n. 4, p. 369-378, 2001.

BARTHOLO, Tiago Lisboa et al. Formando jogadores de futebol: o impacto do tempo de treinamento na formação escolar de jovens espanhóis e brasileiros. In: CONGRESSO 
BRASILEIRO DE CIÊNCIAS DO ESPORTE, 17., 2011, Porto Alegre. Anais eletrônicos... Disponível em: <http://cbce.tempsite.ws/congressos/index.php/XVII CONBRACE/2011/paper/ viewFile/3065/1557>. Acesso em: 18 maio 2012.

BOURKE, Ann. The dream of being a professional soccer player: insights on career development options of young Irish players. Journal of Sport and Social Issues, v. 27, n. 4, p. 399-419, 2003.

CHRISTENSEN, Mette Krogh; SØRENSEN, Jan Kahr. Sport or school? Dreams and dilemmas for talented young Danish football players. European Physical Education Review, v. 15, n. 1, p. 115-137, 2009.

COLLINS, Michael Frank; BULLER, James. Social Exclusion from High-Performance Sport: Are all talented Young Sports People being given an Equal Opportunity of Reaching the Olympic Podium? Journal of Sport and Social Issues, v. 27, n. 4, p. 420-442, 2003.

CORREIA, Carlus Augustus Jourand. Entre a profissionalização e a escolarização: projetos e campo de possibilidades em jovens atletas do Colégio Vasco da Gama. Rio de Janeiro, 2014. 240 f. Dissertação (Mestrado em Educação) - Programa de Pós- Graduação da Faculdade de Educação no Centro de Filosofia e Ciências Humanas da Universidade Federal do Rio de Janeiro, Rio de Janeiro, 2014.

COSTA, Felipe Rodrigues da. A escola, o esporte e a concorrência entre estes mercados para jovens atletas mulheres no futsal de Santa Catarina. 2012. 109 f. Tese (Doutorado em Educação Física) - Programa de Pós-Graduação em Educação Física, Universidade Federal do Rio de Janeiro, Rio de Janeiro, 2012.

DAMO, Arlei Sander. Do dom à profissão: uma etnografia do futebol de espetáculo a partir de formação de jogadores no Brasil e na França. 2005. 434 f. Tese (Doutorado em Antropologia Social) Programa de Pós-Graduação em Antropologia Social da Universidade Federal do Rio Grande do Sul, Porto Alegre, 2005.

GOLDBERG, Alan; CHANDLER, Timothy. Sports Counseling: Enhancing the Development of the high school student-athlete. Journal of Counseling and Development, v. 74, n. 1, p. 39-44, 1995.

HAMILTON, Mary. Howard; SINA, Julie. How college affects Sudents Athletes. New Directions for students athletes, n. 93, p.35-45, 2001

HICKEY, Christopher; KELLY, Peter. Preparing to not be a footballer: higher education and professional sport. Sport, Education and Society, v. 13, n. 4, p. 477-494, 2008.

KAY, Tess. Sporting excellence: a family affair? European Physical Education Review, v. 6, n. 2, p. 151-169, 2000.

LEE, Courtland. An Investigation of the Career Expectations of High School Students Athletes. The Personnel and Guidance, v. 61, n. 9, p. 544-547, 1983.

LÉVY, Pierre. 0 que é virtual? Rio de Janeiro: Editora 34, 1996.

MATOS, Juliana Cassani et al. A produção acadêmica sobre conteúdos de ensino na educação física escolar. Movimento, v. 19, n. 2, p. 123-148, 2013

MCGILLIVRAY, David; MCINTOSH, Aaron. 'Football is my life': theorizing social practice in the

Scottish professional football field. Sport in Society, v. 9, n. 3, p. 371-387, 2006. 
MELO, Leonardo Bernardes Silva de. Formação e escolarização de jogadores de futebol no Estado do Rio de Janeiro. 2010. 72 f. Dissertação (Mestrado em Educação Física)- Programa de Pós-Graduação em Educação Física da Universidade Gama Filho, Rio De Janeiro, 2010.

MOROSINI, Marília Costa et al. A produção científica sobre educação superior no Brasil: 19682000. Porto Alegre: GT Política de Educação Superior/Anped, 2002. Disponível em: <http://www. pucrs.br/faced/pos/universitas/>. Acesso em: 5 jun. 2012.

PARKER, Andrew. Training for "glory", schooling for "failure"?: English professional football, traineeship and educational provision. Journal of Education and Work, v. 13, n. 1, p. 61-76, 2000.

PRONI, Marcelo Weishaupt. A metamorfose do futebol. Campinas: Unicamp. 2000.

RIAL, Carmem. Jogadores brasileiros na Espanha: emigrantes porém... Revista de Dialectología y Tradiciones Populares, v. 61, n. 2, p. 163-190, 2006.

ROCHA, Hugo Paula Almeida da et al. Jovens esportistas: profissionalização no futebol e a formação na escola. Motriz, v. 17, n. 2, p. 52-263, 2011.

ROCHA, Hugo Paula Almeida da. A escola dos jóqueis: a escolha de carreira do aluno atleta. Rio de Janeiro, 2013. 242 f. Dissertação (Mestrado em Educação)- Programa de Pós-Graduação em Educação da Universidade Federal do Rio de Janeiro, Rio de Janeiro, 2013.

ROMANOWSI, Joana Paulin; ENS, Romilda Teodoro. As pesquisas denominadas do tipo "Estado da Arte" em educação. Revista Diálogo Educacional, v. 19, n. 2, p. 37-50, set./dez. 2006.

SACK, Allen. College Sport and the Student-Athlete. Journal of Sport and Social Issues, v. 11, n.12, p. 31-47, 1987.

SACK, Allen; THIEL, Robert. College football and social mobility: a case study of Notre Dame football players. Sociology of Education, v. 52, n. 1, p. 60-66, 1979.

SCHWARTZMAN, Simon; COSSIO, Maurício Blanco. Juventude, educação e emprego no Brasil. Cadernos Adenauer: Geração Futuro, v. 7, n. 2, p. 51-65, 2007.

SINGER, John; MAY, Reuben Buford. The career trajectory of a black male high school basketball player: A social reproduction perspective. International Review for the Sociology of Sport, v. 46, n. 3, p. 299-314, 2011

SOARES, Antonio Jorge Gonçalves; ROCHA, Hugo Paula Almeida da; COSTA, Felipe Rodrigues da. A escola dos jóqueis: a aposta de carreira do aluno-atleta. In: CONGRESSO BRASILEIRO DE SOCIOLOGIA, 15, 2011. Anais... Curitiba, 2011

SOARES, Antonio Jorge Gonçalves et al. Jogadores de futebol no Brasil: mercado, formação de atletas e escola. Revista Brasileira de Ciências do Esporte, n. 33, p. 905-921, dez. 2011. 
